\title{
PRACTICE REPORT
}

\section{An Academic Multihealth System PGY2 Pediatric Pharmacy Residency Program}

\author{
Theresa Klosterman, PharmD, ${ }_{1}^{1}$ Rachel Meyers, PharmD, 2,3 Anita Siu, PharmD, ${ }^{2,4}$ Pooja Shah, PharmD, ${ }^{2,5}$ Katelin \\ Kimler, PharmD, 2,5 Marc Sturgill, PharmD, ${ }^{2,6}$ and Christine Robinson, PharmD ${ }^{2,7}$ \\ ${ }^{1}$ Saint Luke's Hospital, Chesterfield, Missouri, ${ }^{2}$ Ernest Mario School of Pharmacy, Rutgers The State University \\ of New Jersey, Piscataway, New Jersey, ${ }^{3}$ Saint Barnabas Medical Center, Livingston, New Jersey, ${ }^{4}$ Jersey Shore \\ University Medical Center, Neptune, New Jersey, ${ }^{5}$ Hackensack University Medical Center, Hackensack, New Jersey, \\ ${ }^{6}$ Rutgers-Robert Wood Johnson Medical School, New Brunswick, New Jersey, ${ }^{7}$ Morristown Medical Center, \\ Morristown, New Jersey
}

\begin{abstract}
We describe a novel multihealth system pediatric pharmacy residency program through the Ernest Mario School of Pharmacy at Rutgers University. Pediatric clinical pharmacy is a growing field that has seen an increase in demand for practitioners. Practice sites include freestanding children's hospitals, children's hospitals within adult hospitals, and pediatric units within adult hospitals. To accommodate a residency program in a region with no freestanding children's hospital, the pediatric faculty members at the Ernest Mario School of Pharmacy at Rutgers University developed a multihealth system postgraduate year 2 (PGY2) pediatric pharmacy residency program with 6 pediatric faculty members functioning as preceptors at their 5 respective practice sites. The multihealth system setup of the program provides the resident exposure to a multitude of patient populations, pediatric specialties, and pediatric pharmacy practices. In addition, the affiliation with Rutgers University allows an emphasis on academia with opportunities for the resident to lecture in small and large classrooms, facilitate discussion periods, assist with clinical laboratory classes, and precept pharmacy students. The resident has the unique opportunity to develop a research project with a large and diverse patient population owing to the multihealth system rotation sites. A multihealth system PGY2 residency in pediatric pharmacy provides the resident a well-rounded experience in pediatric clinical practice, research, and academia that will enhance the resident's ability to build his or her own pediatric pharmacy practice.
\end{abstract}

INDEX TERMS: hospitals, internship and residency, pediatric pharmacy, universities

J Pediatr Pharmacol Ther 2015;20(6):468-475

\section{INTRODUCTION}

Pharmacy residency programs are essential to the shift in pharmacy practice to more cognitive and direct patient or health care-provided services. ${ }^{1}$ The American College of Clinical Pharmacy (ACCP) and American Society of HealthSystem Pharmacists (ASHP) House of Delegates recommended that by 2020 all pharmacists who provide direct patient care should be required to complete a residency. ${ }^{2,3}$ However, as of 2008, the number of postgraduate year (PGY) 1 positions available would only allow $16 \%$ of graduates to complete a PGY1 residency immediately after graduation. ${ }^{1}$ This statistic has improved recently: for the year 2012-2013, a total of 13,551 students received their doctor of pharmacy degree, ${ }^{4}$ and 2691 PGY1 positions were available, ${ }^{5}$ which would allow $19.9 \%$ of graduates to complete a PGY1 residency. Not all pharmacy residency programs are accredited by ASHP, so this number may be an underestimation.

The demand for pharmacy residency programs now far exceeds the number of positions available. In 2014, 36.3\% of PGY1 and 32.1\% of PGY2 applicants participating in the ASHP Resident Matching Program ("The Match") did not match. ${ }^{6}$ Further, there was an $11 \%$ and $12 \%$ rise in the number of candidates applying for PGY1 and PGY2 pharmacy residencies in 2014 in comparison to 2013, respectively. 5,6 These numbers do not include individuals who are able to 
obtain a residency during the postmatch process or those who complete non-accredited programs. The number of programs and positions is also increasing but is currently unable to fulfill the demand of candidates. In 2014, there were 901 PGY1 programs with 2541 positions; this was an increase from 2013 of $6.2 \%$ and $6.1 \%$, respectively. PGY2 programs in pediatrics saw an increase of $7.3 \%$ to 44 programs participating in The Match in 2014 versus 2013, with a total of 58 positions (an increase of $11.5 \%$ ). 5,6

PGY1 programs can receive pass-through funding through the Centers for Medicare and Medicaid Services if the hospital has a certain percentage of Medicare patients. This federal funding is provided to hospitals to support graduate medical education. Unfortunately this funding is not available for PGY2 programs, thus diminishing but not eliminating the incentive for their creation. According to the Pediatric Pharmacy Advocacy Group (PPAG) residency directory, there are 68 pediatric pharmacy residency programs (24 PGY1, 35 PGY2, and 9 unspecified), each of which train an average of 1 to 2 residents per year. ${ }^{7}$ According to the ASHP residency directory, there are 46 pediatric programs that are either accredited by ASHP or in precandidate, candidate, or preliminary status. ${ }^{8}$

In 2008, the Joint Commission ${ }^{9}$ issued Sentinel Event Alert No. 39 emphasizing the increased risk of medication errors in pediatric patients. The alert highlighted the need for specialtytrained pediatric pharmacists. In addition, the American Academy of Pediatrics has emphasized the benefit of and need for pediatric-trained pharmacists. ${ }^{10,11}$ More pediatric residency-trained pharmacists would be required to meet the aim described in the 2013 white paper issued by the Pediatrics Practice and Research Network of the ACCP and PPAG, ${ }^{12}$ emphasizing the need for improved access to pediatric clinical pharmacy services for all pediatric patients while providing a framework for expanded training. One specific statement by this white paper indicates the need for additional PGY2 pediatric pharmacy residency programs. In addition, a recent commentary from ACCP describes the inadequate supply of PGY2-trained clinical pharmacy specialists, including pediatrics. ${ }^{13}$

Pediatric residency-trained pharmacists are also needed in schools and colleges of pharmacy. In response to the national shortage of pharma- cists that existed in the late 1990s, there has been a significant rise in the number of pharmacy schools in the United States; 80 schools and colleges of pharmacy offered a PharmD degree in $2000,{ }^{14}$ compared to 133 programs that are either accredited or in candidacy for accreditation as of July 2014. ${ }^{4}$ Due to the rapid expansion of pharmacy schools, there is now an inadequate quantity of pharmacy faculty to accommodate the increased number of pharmacy schools. ${ }^{15}$ For the academic year 2012-2013, a total of 119 colleges and schools of pharmacy reported 473 vacant and/or lost positions, a $14.8 \%$ increase from the year prior; $52.9 \%$ of these positions were in clinical science/pharmacy practice. ${ }^{16}$

There is a clear need for additional PGY2 pediatric pharmacy residency programs. Moreover, programs that provide exposure within a school of pharmacy may encourage residents to pursue faculty appointments and help alleviate the need for faculty members in pediatrics. The purpose of this article is to describe a novel PGY2 multihealth system pediatric pharmacy residency program developed in affiliation with a school of pharmacy.

\section{PROGRAM BACKGROUND}

In 2010, the Ernest Mario School of Pharmacy at Rutgers, The State University of New Jersey, began offering a multihealth system PGY2 pediatric pharmacy residency, with all of the school's pediatric faculty members serving as preceptors. The school is located in Piscataway, New Jersey. There are 6 pediatric pharmacy faculty positions at Rutgers, with 5 practice sites within New Jersey: Hackensack University Medical Center (HUMC) in Hackensack, Jersey Shore University Medical Center (JSUMC) in Neptune, Morristown Medical Center (MMC) in Morristown, Saint Barnabas Medical Center (SBMC) in Livingston, and Robert Wood Johnson University Hospital (RWJUH) in New Brunswick, which is the primary teaching site for Rutgers-Robert Wood Johnson Medical School (RWJMS). The residency program director practices at MMC.

Since each site is in a different region of New Jersey, the patient populations and specialties vary among sites. Each of the practice sites is located within 45 miles of the school of pharmacy. Four of the 5 sites have children's hospitals within an adult hospital: the Joseph M. Sanzari Chil- 
Table 1. Clinical Pharmacy Practice Areas Available at Each Site

\begin{tabular}{lccccc}
\hline Practice Site & \multicolumn{5}{c}{ Practice Areas } \\
\cline { 2 - 5 } & $\begin{array}{c}\text { Pediatric } \\
\text { Medicine }\end{array}$ & PICU & NICU & $\begin{array}{c}\text { Pediatric } \\
\text { Emergency Room }\end{array}$ & $\begin{array}{c}\text { Hematology/ } \\
\text { Oncology }\end{array}$ \\
\hline HUMC & $\mathrm{X}$ & $\mathrm{X}$ & $\mathrm{X}$ & $\mathrm{X}$ & $\mathrm{X}$ \\
JSUMC & $\mathrm{X}$ & $\mathrm{X}$ & $\mathrm{X}$ & $\mathrm{X}$ & $\mathrm{X}$ \\
MMC & $\mathrm{X}$ & $\mathrm{X}$ & $\mathrm{X}$ & $\mathrm{X}$ & $\mathrm{X}$ \\
SBMC & $\mathrm{X}$ & $\mathrm{X}$ & $\mathrm{X}$ & \\
\hline HUMC, Hackensack University Medical Center; ISUMC, Jersey Shore University Medical Center; MMC, Morristown Medical Center; NICU, \\
neonatal intensive care unit; PICU, pediatric intensive care unit; SBMC, Saint Barnabas Medical Center
\end{tabular}

dren's Hospital at HUMC (105 licensed beds), the K. Hovnanian Children's Hospital at JSUMC (75 licensed beds), the Bristol-Myers Squibb Children's Hospital at RWJUH (100 licensed beds), and the Goryeb Children's Hospital at MMC (113 licensed beds); the fourth hospital, SBMC, does not have a separate children's hospital, but does have 97 beds allotted to pediatric patients. Each hospital has a pediatric intensive care unit (PICU), neonatal intensive care unit (NICU), and general pediatrics floor, with pediatric specialists in more than 30 areas of medical and surgical care, excluding pediatric cardiac surgery.

All of the practice sites are community teaching institutions, with affiliations to various medical schools. The clinical pharmacy practice areas offered at each site are summarized in Table 1. Clinical services provided by the faculty members are similar at each site, including participation in patient care rounds, antibiotic pharmacokinetic monitoring, and consultation services as needed for physicians, nurses, and pharmacy staff. The 5 clinical preceptors for the program are each cofunded by the University and the practice site. The sixth (research) preceptor is a tenure-track faculty member fully funded by the University.

\section{EDUCATIONAL OUTCOMES, GOALS, AND OBJECTIVES}

The PGY2 pediatric pharmacy residency at Rutgers is currently not accredited by ASHP. While accreditation is considered ideal, it has not been financially feasible for a program of this type as of yet. Currently, ASHP charges a fee for each site that it visits, and since the Rutgers program is divided between 5 sites, the cost of accreditation and reaccreditation for the program would be significant.

While the program is not accredited, the educational outcomes, goals, and objectives for PGY2 pediatric pharmacy residencies provided on the ASHP Web site ${ }^{17}$ serve as the framework by which the Rutgers residency program is structured. Each preceptor is responsible for choosing the outcomes, goals, and objectives that they feel should be assessed on their respective rotations. These may be adjusted on the basis of individual needs and goals of the resident. The residency program director is responsible for ensuring that all goals and objectives are assessed. Written feedback on progress toward these outcomes is provided to the resident and forwarded to the residency program director. Verbal self-evaluation by the resident is expected and discussed between the resident and preceptor; self-evaluations will be written in the future. Currently, there is no requirement for the percentage of objectives that must be obtained in order to successfully complete the residency, but this is being discussed and is a future goal of the program.

\section{ROTATIONS}

The residency consists of clinical rotations at 4 institutions (HUMC, JSUMC, MMC, SBMC) and a research rotation at the fifth institution (RWJMS). A minimum of 1 to 2 months is spent at each clinical rotation site and 1 month is spent at the research rotation site. An additional month is spent at MMC to optimize exposure in the pediatric and neonatal pharmacy satellites, since there is no staffing requirement for the residency. The rotation options at each site are described in Table 2.

Since each of the hospitals have relatively small PICU, NICU, and general pediatric services, the resident is frequently able to gain exposure to multiple areas during each rotation. The resident 
Table 2. Rotations Offered at Each Rotation Site

\begin{tabular}{|c|c|c|c|c|c|c|c|c|}
\hline $\begin{array}{l}\text { Practice } \\
\text { Site }\end{array}$ & $\begin{array}{c}\text { General } \\
\text { Pediatrics }\end{array}$ & PICU & NICU & $\begin{array}{l}\text { Ambulatory } \\
\text { Care Clinics }\end{array}$ & $\begin{array}{l}\text { Hematology/ } \\
\text { Oncology/ } \\
\text { Bone Marrow } \\
\text { Transplant }\end{array}$ & $\begin{array}{c}\text { Pediatric } \\
\text { Emergency } \\
\text { Room }\end{array}$ & $\begin{array}{c}\text { Pediatric/ } \\
\text { Neonatal } \\
\text { Satellite } \\
\text { Pharmacy }\end{array}$ & Research \\
\hline HUMC & $x$ & $x$ & $x$ & & $x$ & & & \\
\hline JSUMC & $x$ & $x$ & $x$ & $x$ & & & & \\
\hline MMC & $x$ & $x$ & $x$ & $x$ & $x$ & & $x$ & \\
\hline RWJMS & & & & & & & & $X$ \\
\hline SBMC & $x$ & $x$ & & & & $x$ & & \\
\hline
\end{tabular}

spends the first 2 months at SBMC rounding in both the general pediatric and PICU units. A short rotation (2 weeks) in the pediatric emergency room is also available at SBMC. The September through November months are spent at MMC in the NICU and general pediatrics units. Exposure to pediatric hematology/oncology, infectious diseases, or additional PICU time is also available at MMC depending on the needs and interests of the resident. December is used as a research month and is usually spent in the Department of Pediatrics at RWJMS with the research project preceptor.

January and February are spent at JSUMC and focus on ambulatory care rotations. The resident spends 1 month in 2 of the following pediatric clinics: pulmonary, endocrinology, neurology, and infectious diseases. During off-clinic hours / days, the resident rounds with the general pediatrics team. The resident spends time at HUMC during March, April, and May where there are 2 faculty preceptors. Rotations at HUMC are chosen on the basis of the resident's needs and interests at that point during the residency year. Options include hematology/oncology, NICU, nutrition, bone marrow transplantation, pain and palliative care, and infectious diseases. During the final month of the residency, the resident has the option to return to a previous site, based on his or her needs. Usually at this point in the rotation the resident has found a job, and this month is flexible in order to allow the resident a chance to receive further training in the area in which he or she will be practicing.

The practice sites each have a wide range of services, which gives the resident an opportunity to be exposed to a number of different disease states and specialties. Three of the 4 clinical rotation sites are trauma centers, one has a large renal transplant center, and one has the burn center for the state of New Jersey. Because of its multi-institutional setup, the resident is able to take part in patient care with a wide variety of patients. In addition, the resident is mentored by 6 experienced pediatric clinicians who each have different styles and strengths.

\section{ACADEMIA}

Considering the growing number of pharmacy schools and the corresponding need for clinical faculty and preceptors, ${ }^{15,16}$ educating residents to be effective teachers and leaders in pharmacy practice is a priority for the profession. The Rutgers PGY2 Pediatric Pharmacy Residency has a heavy emphasis on academia and leadership. The resident is appointed as a clinical instructor at the Ernest Mario School of Pharmacy through participation as a teaching assistant in the Introduction to Physical Assessment and Pharmacy Communications courses. Further, the pediatric faculty members' team teaches a pediatric elective titled "Pediatric Pharmacotherapy" in the spring semester. The resident creates and presents didactic lectures and patient cases in the Pediatric Pharmacotherapy course and facilitates the development and implementation of a Poison Prevention Program for students at a local preschool. In addition, the resident prepares and facilitates a pediatric case for the Advanced Pharmacotherapy Applications elective. The resident presents a North American Pharmacy Licensing Examination (NAPLEX) pediatrics review lecture to the entire Ernest Mario School of Pharmacy 
fourth-professional-year class ( 200 students) in the spring. The resident has been given verbal feedback after lectures and precepting experiences. Written evaluations of precepting have recently been added and written evaluations for lectures will begin in the coming months. Student feedback has not been collected; however, it is being considered for the future.

In 2012, the Ernest Mario School of Pharmacy began offering a teaching and learning certificate program for pharmacy residents and fellows; participation is required of the pediatric pharmacy resident, unless he or she has already completed a similar program, in which case he or she will help facilitate the program.

Further opportunities for presenting to large groups include continuing education lectures to pharmacists at Meridian Health, JSUMC's hospital network, MMC, Garden State PPAG chapter meetings, and for the Rutgers University Office of Continuing Education programs.

Training in experiential education occurs throughout the year. The residency preceptors are all faculty members, thus the resident will have ample experience in assisting with precepting students on advanced pharmacy practice experience (APPE) rotations and hospital-based PGY1 pharmacy residents, and will serve as the primary preceptor for an APPE student in the last month of his or her residency, which corresponds to the first rotation cycle for a new class of fourthprofessional-year students.

Presentation skills are refined throughout the residency, with journal club discussions and formal case presentations occurring at the individual practice sites, and a 45-minute seminar presentation at the end of each of the resident's rotations, presented to all of the preceptors at Rutgers.

\section{RESEARCH}

A focused research rotation is conducted with a pediatric faculty member who is the assistant director of the Pediatric Clinical Research Center at RWJMS. The resident must complete 2 research projects throughout the residency. The first project is designed to be completed and presented at the University HealthSystem Consortium (UHC) Pharmacy Council meeting in December. The second research project involves all 4 of the clinical rotation sites and is to be performed as a platform presentation at the PPAG Annual Meeting. Therefore, for the second project, 5 institutional review board (IRB) approvals must be granted before data collection: one for each of the 4 institutions where data collection is completed (MMC, SBMC, HUMC, and JSUMC) and one for Rutgers. The opportunity to conduct multihealth system research projects allows the resident to greatly expand his or her patient population and create a large-scale residency research project.

The research month is conducted between the resident's second and third clinical rotations. At this point in the year, IRB approvals should be complete and data collection should be well under way. The month allows the resident time to refine data analysis skills and begin writing a manuscript on the research, which should be submitted for publication.

\section{PROGRAM BENEFITS}

Patients, sponsoring institutions, student pharmacists, PGY1 pharmacy residents, and the pediatric pharmacy faculty all benefit from the residency program. Although all of the institutions have at least 1 pediatric clinical faculty pharmacist, more pediatric service rounding teams would greatly benefit from the participation of a pediatric clinical pharmacist. The addition of a resident for even 2 months of the year to each site allows additional pediatric services to experience a regular pharmacist presence on multidisciplinary rounds. Further, the resident provides at least 1 educational lecture at each practice site to medical students and residents (noon conference), pharmacists and technicians (continuing education program), or nurses (new nurse orientation, nursing education seminars, etc.).

The resident is a great asset in assisting with precepting APPE students and hospital-based PGY1 pharmacy residents, leading patient and topic discussions, and providing support for the students if the preceptor is off-site. This allows the students to maintain continued active learning during times in which the main preceptor may not be available.

A measureable benefit of the residency program is the research publications that have been produced. Between its inception in 2010 and March 2015, three peer-reviewed publications have been written, with more in development. 
Two of these publications were multisite research studies.

\section{CHALLENGES}

All of the pediatric faculty members at the clinical rotation sites are involved in the resident's large-scale multihealth system research project. As a result, all of the preceptors are coinvestigators for each other's institutions and must satisfy all the research requirements at each institution. Although the residency has been in existence since 2010 and the preceptors have satisfied each institution's IRB qualifications, these qualifications change with time and require that new courses be taken, which has led to delays in IRB approval. Each IRB has a different format for submission and timeline for approval. The preceptors now provide the resident an overview of the full IRB process at each institution and outline the steps the resident can take to ensure a timely approval process.

Although the resident spends time observing the pharmacists in the neonatal and pediatric pharmacy satellites at MMC, one vital piece of a typical residency program that our program lacks is a staffing component. Since the resident is an employee of Rutgers University rather than any of the practice sites, the resident cannot fully function as a pharmacist and is not credentialed as such at the hospitals. The resident is given pharmacy student-level access to medical information. The ability to verify orders and access systems such as automated dispensing cabinets enhances the resident's role on the team, and the resident in our program unfortunately does not have this access. Staffing is critical for the resident to learn and understand the complete process of pediatric pharmacy, and options to establish this experience are being sought. Despite the lack of a staffing component, residents do assist in reviewing medication orders and assisting physicians with order entry and product selection. The residents also participate in each hospital's Pharmacy and Therapeutics Committee meetings in order to gain exposure to the process of formulary management and guideline development and its implications for pediatric patients.

Another challenge has been keeping track of resident development, since the preceptors are at different sites and geographic locations. To overcome this, the preceptors meet and discuss the residents' performance and their progress throughout the year, particularly after the seminar presentation at the end of each rotation. In addition, the preceptors communicate directly with the residency program director to provide feedback both verbally and in writing via the formal evaluation process.

Travel has been another obstacle, and residents often have to be at both their rotation site and the school of pharmacy in the span of the same day. Most residents have chosen to live centrally so that their commute is usually 30 minutes or less to each site.

\section{INITIAL SUCCESS}

To date, each resident has successfully completed the program (Table 3 ) and 3 of the 4 have been offered a clinical pediatric pharmacist position. The goal of presenting a poster at the UHC Pharmacy Council Meeting and a platform presentation at the PPAG annual meeting has been achieved each year. One research grant has been awarded and 3 research manuscripts have been published, ${ }^{18-20}$ with others in various stages of development.

\section{FUTURE DIRECTIONS}

Even with the program's early success, there is still opportunity for growth. Streamlining the IRB approval process will greatly ease early frustration in the research process. Opportunities for greater collaboration in research also exist, both with other hospitals in the local PPAG chapter and the Rutgers Institute for Pharmaceutical Fellowships. Expanding the residency program to 2 or more residents is another goal, and would be easily accommodated given the number of preceptors and practice sites, but has financial limitations at this time.

\section{CONCLUSION}

A multihealth system PGY2 pediatric pharmacy residency program is a novel concept that expands resident exposure to diverse patient populations and specialties with the advantage of allowing the resident to experience the practice of pediatric pharmacy from the perspective of multiple institutions and practitioners. 
Table 3. Requirements for Successful Completion of the Program

\begin{tabular}{|c|c|}
\hline Program Requirement & Quantity \\
\hline \multicolumn{2}{|l|}{ Rotations (mo)* } \\
\hline Ambulatory care & 2 \\
\hline Elective & 1 \\
\hline General pediatrics & 2 \\
\hline Hematology/oncology & 1 \\
\hline $\mathrm{NICU}$ & 1 \\
\hline Pediatric/neonatal satellite & 1 \\
\hline Pediatric nutrition & 1 \\
\hline $\mathrm{PICU}$ & 2 \\
\hline Research & 1 \\
\hline \multicolumn{2}{|l|}{ Presentations } \\
\hline Clinical seminars & 4 \\
\hline Lectures to pharmacy students & 2 \\
\hline $\begin{array}{l}\text { Case discussions to student pharmacists (in the Pediatric Pharmacotherapy elective and the } \\
\text { Advanced Pharmacotherapy Applications elective at EMSOP) }\end{array}$ & 3 \\
\hline Continuing education to pharmacists & 2 \\
\hline Lectures to medical residents & 2 \\
\hline Lectures to nurses & 2 \\
\hline Journal club presentations & 2 \\
\hline \multicolumn{2}{|l|}{ Research } \\
\hline Poster presentation at UHC Pharmacy Council December meeting & 1 \\
\hline Platform Presentation at PPAG Annual Meeting & 1 \\
\hline
\end{tabular}

EMSOP, Ernest Mario School of Pharmacy; NICU, neonatal intensive care unit; PICU, pediatric intensive care unit; PPAG, Pediatric Pharmacy Advocacy Group; UHC, University HealthSystem Consortium

*Rotations may overlap; for example, the resident may round with both the PICU and general pediatrics teams during the same month

Disclosure The authors declare no conflicts or financial interest in any product or service mentioned in the manuscript, including grants, equipment, medications, employment, gifts, and honoraria.

Acknowledgments The authors would like to gratefully acknowledge Joseph Barone, PharmD, FCCP, Dean of the Ernest Mario School of Pharmacy, for his enthusiastic support of this program. We would also like to acknowledge Lisa Degnan, PharmD, Francia Kellner, MS, RPh, and Suzannah Kokotajlo, PharmD, for their continued support and assistance in precepting our residents. In addition, we would like to thank Lauren Aleksunes, PharmD, PhD, for her cooperation and assistance in research efforts.

Abbreviations ACCP, American College of Clinical Pharmacy; APPE, Advanced Pharmacy Practice Experience; ASHP, American Society of Health-System Pharmacists; HUMC, Hackensack University Medical Center; IRB, institutional review board; JSUMC, Jersey Shore University Medical Center; MCM, Midyear Clinical Meeting; MMC,
Morristown Medical Center; NICU, neonatal intensive care unit; PGY1, postgraduate year 1; PGY2, postgraduate year 2; PharmD, doctor of pharmacy; PICU, pediatric intensive care unit; PPAG, Pediatric Pharmacy Advocacy Group; RWJMS, Rutgers-Robert Wood Johnson Medical School; RWJUH, Robert Wood Johnson University Hospital; SBMC, Saint Barnabas Medical Center; UHC, University HealthSystem Consortium

Correspondence Rachel Meyers, PharmD, Ernest Mario School of Pharmacy, Rutgers, The State University of New Jersey, 160 Frelinghuysen Rd, Piscataway, NJ 08854, email: rachel.meyers@pharmacy.rutgers.edu

\section{REFERENCES}

1. Shannon SB, Bradley-Baker LR, Truong HA. Pharmacy residencies and dual degrees as complementary or competitive advanced training opportunities. Am J Pharm Educ. 2012;76(8):145. 
2. Murphy JE, Nappi JM, Bosso JA, et al. American College of Clinical Pharmacy's vision of the future: postgraduate pharmacy residency training as a prerequisite for direct patient care practice. Pharmacotherapy. 2006;26(5):722-733.

3. ASHP Policy Positions 1982-2013, American Society of Health-System Pharmacists. http:/ / www.ashp.org/DocLibrary/ BestPractices/policypositionsandrationales2013.aspx. Accessed July 9, 2014.

4. Academic Pharmacy's Vital Statistics. American Association of Colleges of Pharmacy. http://www.aacp.org/about/Pages/Vitalstats.aspx. Accessed March 6, 2015.

5. National Matching Services Inc. ASHP Resident Matching Program. Summary of programs and positions offered and filled for the 2013 Match. https://www.natmatch. com/ashprmp/stats/2013summpos.html. Accessed March 9, 2015.

6. National Matching Services Inc. ASHP resident matching programs: summary results of the match for positions beginning in 2014. https: / / natmatch.com/ashprmp/ stats/2014applstats.html. Accessed July 9, 2014.

7. Pediatric Pharmacy Advocacy Group Web site residency directory. http:// www.ppag.org/en/directories/search. asp? category=Residencies. Accessed December 18, 2014.

8. ASHP online residency directory. http:// accred.ashp.org/aps/pages/directory/ residencyProgramSearch.aspx\#1. Accessed December 18, 2014.

9. Joint Commission. Sentinel Event Alert, Issue 39: preventing pediatric medication errors. April 11, 2008. http://www.jointcommission.org/assets/1/18/SEA_39. PDF. Accessed February 20, 2015.

10. Committee on Drugs and Committee on Hospital Care, American Academy of Pediatrics. Prevention of medication errors in the pediatric inpatient setting. Pediatrics. 2003;112(2 pt 1):431-436.

11. Rosenberg DI, Moss M; Section on Critical Care and Committee on Hospital Care, American Academy of Pediatrics. Guidelines and levels of care for pediatric intensive care units. Pediatrics. 2004;114(4):11141125.
12. Bhatt-Mehta V, Buck ML, Chung AM, et al. Recommendations for meeting the pediatric patient's need for a clinical pharmacist: a joint opinion of the Pediatric Practice and Research Network of the American College of Clinical Pharmacy and the Pediatric Pharmacy Advocacy Group. Pharmacotherapy. 2013;33(2):243-251.

13. Ragucci KR, O'Bryant CL, Campbell KB, et al. The need for PGY2-trained clinical pharmacy specialists. Pharmacotherapy. 2014;34(6):e65-e73.

14. Brown DL. A looming joblessness crisis for new pharmacy graduates and the implications it holds for the academy. Am J Pharm Educ. 2013;77(5):90.

15. Aistrope DS, Attridge RT, Bickley AR, et al. Strategies for developing pharmacy residents as educators. Pharmacotherapy. 2011;31:65e-70e.

16. American Association of Colleges of Pharmacy. Vacant budged and lost faculty positions: academic year 2012-13. No. 14 . http: / / www.aacp.org/resources/research/institutionalresearch/Documents/ IRB\%20No\%2014\%20-\%20Faculty\%20Vacancies.pdf. Accessed December 18, 2014.

17. American Society of Health Systems Pharmacists. Educational outcomes, goals, and objectives for postgraduate year two (PGY2) pharmacy residencies in pediatrics. http:/ / www.ashp.org/DocLibrary/ Accreditation/Regulations-Standards / RTPObjPediatricMarch2008.pdf. Accessed February 19, 2015.

18. Kokotajlo S, Robinson CA, Presti A. Use of tincture of opium compared to oral morphine for the treatment of neonatal abstinence syndrome. J Opioid Manag. 2013;9(1):62-70.

19. Kokotajlo S, Degnan L, Meyers R, et al. Use of intravenous magnesium sulfate for the treatment of an acute asthma exacerbation in pediatric patients. J Pediatr Pharmacol Ther. 2014;19(2):91-97.

20. Ringenberg T, Robinson C, Meyers R, et al. Achievement of therapeutic vancomycin trough serum concentrations with empiric dosing in neonatal intensive care unit patients. Pediatr Infect Dis J. 2015;34(7):742-747. 